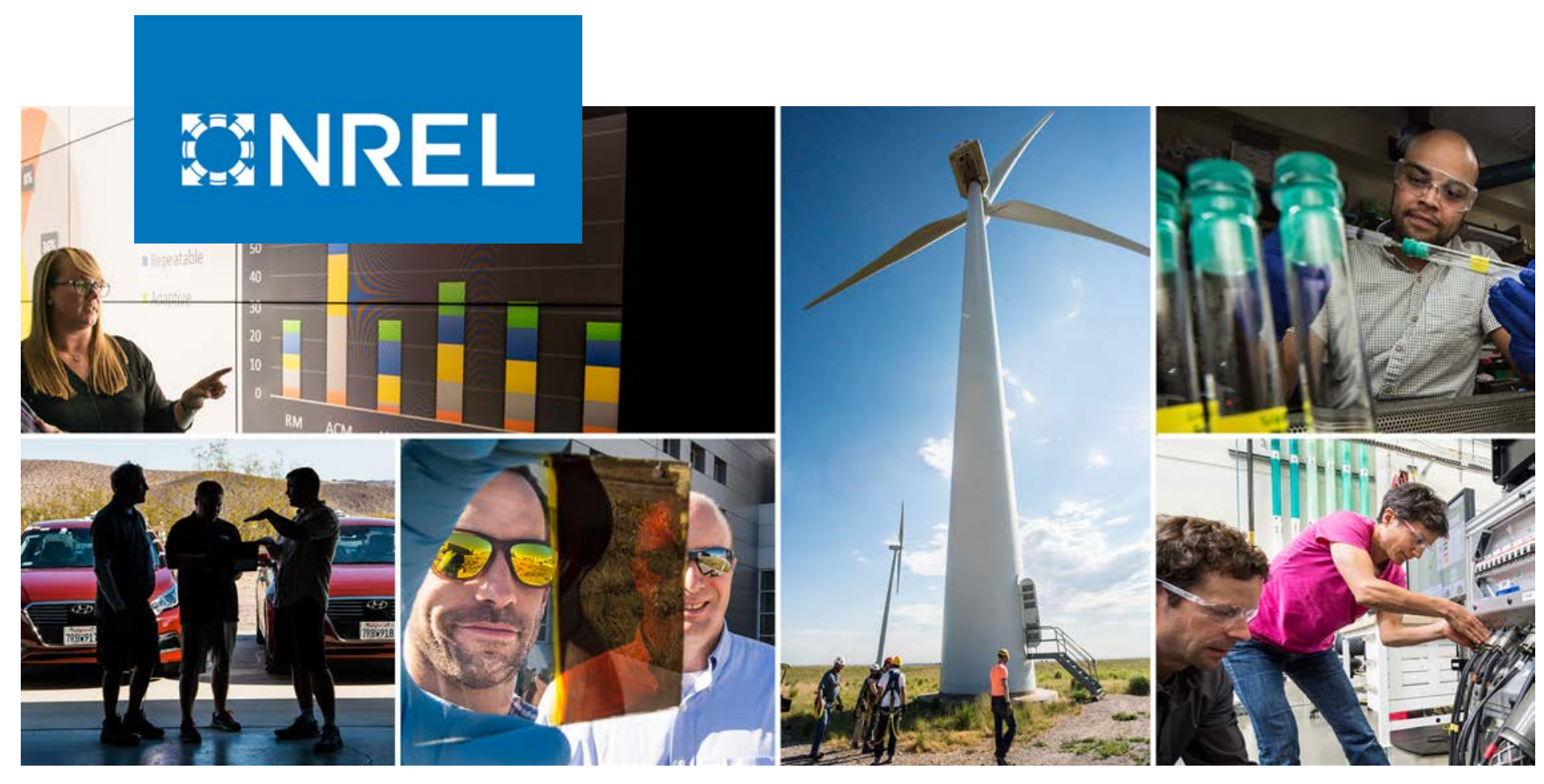

\title{
South Asia Wind and Solar Supply Curves
}

Donna Heimiller, Philipp Beiter, Nick Grue, Galen Maclaurin, and July Tran

National Renewable Energy Laboratory

NREL is a national laboratory of the U.S. Department of Energy

Office of Energy Efficiency \& Renewable Energy

Operated by the Alliance for Sustainable Energy, LLC

This report is available at no cost from the National Renewable Energy Laboratory (NREL) at www.nrel.gov/publications.

\section{Technical Report}

NREL/TP-6A20-71679

October 2018 


\section{GHREL}

\section{South Asia Wind and Solar Supply Curves}

Donna Heimiller, Philipp Beiter, Nick Grue, Galen Maclaurin, and July Tran

National Renewable Energy Laboratory

\section{Suggested Citation}

Heimiller, Donna, Philipp Beiter, Nick Grue, Galen Maclaurin, and July Tran. 2018. South Asia Wind and Solar Supply Curves. Golden, CO: National Renewable Energy Laboratory. NREL/TP-6A20-71679. https://www.nrel.gov/docs/fy19osti/71679.pdf.

NREL is a national laboratory of the U.S. Department of Energy Office of Energy Efficiency \& Renewable Energy Operated by the Alliance for Sustainable Energy, LLC

This report is available at no cost from the National Renewable Energy Laboratory (NREL) at www.nrel.gov/publications.

Contract No. DE-AC36-08GO28308
Technical Report NREL/TP-6A20-71679 October 2018

National Renewable Energy Laboratory 15013 Denver West Parkway Golden, CO 80401 303-275-3000 • www.nrel.gov 


\section{NOTICE}

This work was authored by the National Renewable Energy Laboratory, operated by Alliance for Sustainable Energy, LLC, for the U.S. Department of Energy (DOE) under Contract No. DE-AC36-08G028308. Funding provided by the U.S. Department of State's Bureau of South and Central Asian Affairs Regional Connectivity Program. The views expressed herein do not necessarily represent the views of the DOE or the U.S. Government.

This report is available at no cost from the National Renewable Energy Laboratory (NREL) at www.nrel.gov/publications.

U.S. Department of Energy (DOE) reports produced after 1991 and a growing number of pre-1991 documents are available free via www.OSTI.gov.

Cover Photos by Dennis Schroeder: (clockwise, left to right) NREL 51934, NREL 45897, NREL 42160, NREL 45891, NREL 48097, NREL 46526.

NREL prints on paper that contains recycled content. 


\section{Acknowledgements}

This work was led by U.S. Department of Energy's National Renewable Energy Laboratory (NREL) and funded under the U.S. Department of State's Bureau of South and Central Asian Affairs Regional Connectivity Program. NREL would like to thank the U.S. State Department for their support of this work. The authors would like to thank Anthony Lopez (NREL) and Michael Gleason (DigitalGlobe) for their input to and review of this report, and to Shivani Mathur for her help in gathering input data. The contents of this report are the sole responsibility of NREL and do not necessarily reflect the views of the U.S. Department of State or the United States Government. 


\section{Table of Contents}

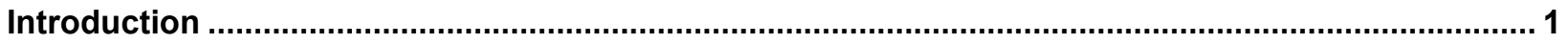

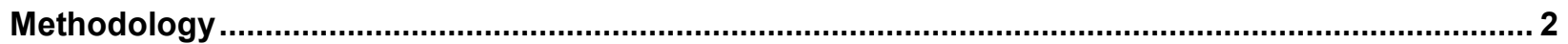

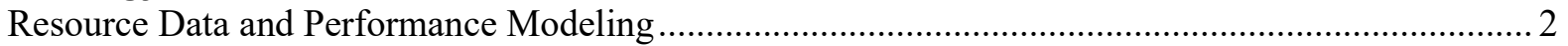

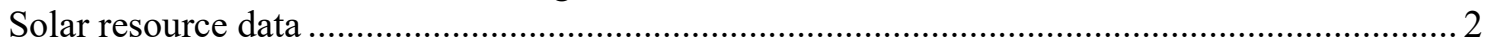

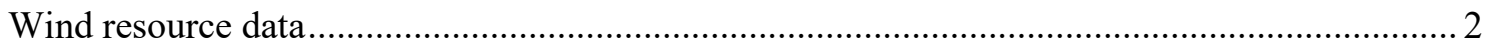

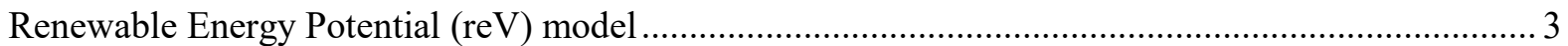

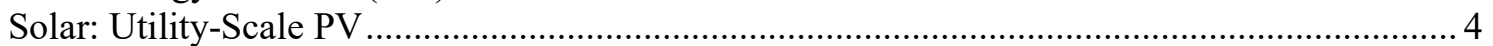

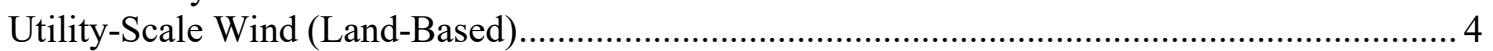

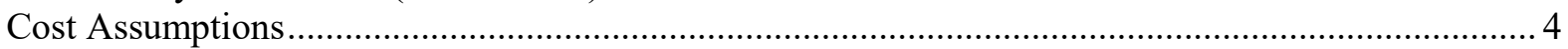

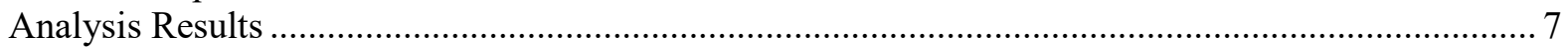

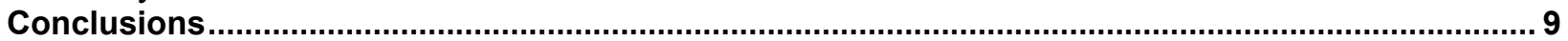

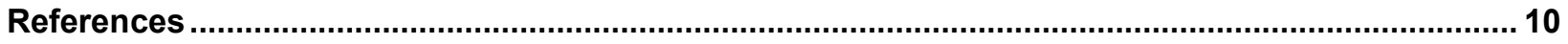

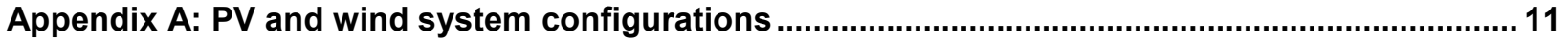

Appendix B: Full utility-scale PV and wind supply curves ....................................................... 13

\section{List of Figures}

Figure 1. 2014 modeled wind resource extent used in this analysis (RED-E India,

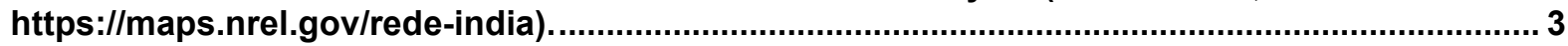

Figure 2. Levelized generation cost (LCOEgen) and total cost (LCOEtot; generation + road +

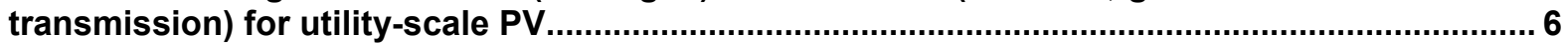

Figure 3. Levelized generation cost (LCOEgen) and total cost (LCOEtot; generation + road +

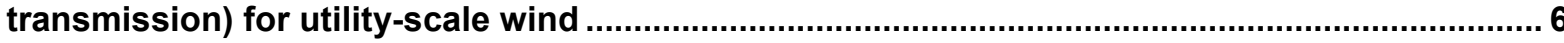

Figure 4. Lowest-cost $10 \mathrm{GW}$, LCOEtot supply curve for utility-scale PV, by country........................ 8

Figure 5. Lowest-cost $10 \mathrm{GW}$, LCOEtot supply curve for wind, by country ...................................... 8

Figure B-1. LCOEgen supply curve for utility-scale PV, by country ..............................................13

Figure B-2. LCOEtot supply curve for utility-scale PV, by country ................................................ 14

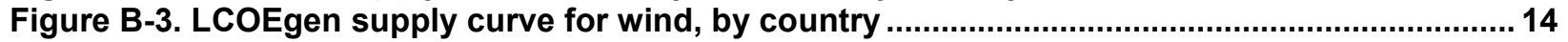

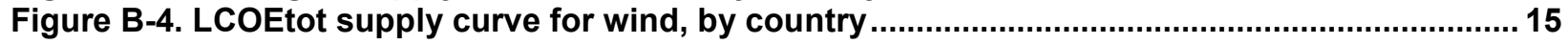

Figure B-5. Lowest-cost $10 \mathrm{GW}$, LCOEgen supply curve for utility-scale PV, by country ................ 15

Figure B-6. Lowest-cost $10 \mathrm{GW}$, LCOEtot supply curve for utility-scale PV, by country.................. 16

Figure B-7. Lowest-cost $10 \mathrm{GW}$, LCOEgen supply curve for wind, by country..................................16

Figure B-8. Lowest-cost 10 GW, LCOEtot supply curve for wind, by country ................................ 17

\section{List of Tables}

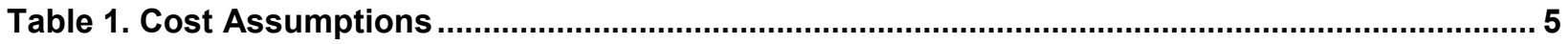

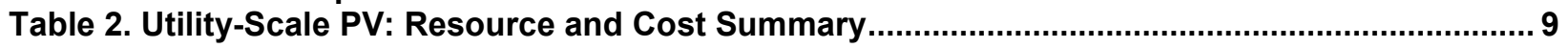

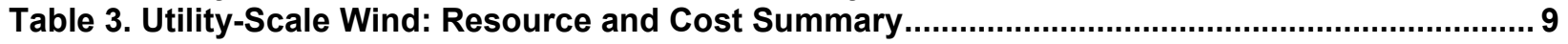




\section{Introduction}

The National Renewable Energy Laboratory (NREL) was funded by the U.S. Department of State through an agreement with the U.S. Department of Energy to provide technical assistance to support increased cross-border electricity trade and cooperation in the South Asia region (including India, Nepal, Bhutan, Bangladesh, and Sri Lanka). The intent of the work was to identify opportunities for, and the associated value of, increased power trade through peer-topeer collaborations, power system modeling, regulatory roadmaps, and improved data. This technical assistance will contribute to future development of a more robust regional energy market, bolster the potential for cross-border connectivity in South Asia, and enable growth of energy production in the region, including from renewable energy (RE).

The focus of this paper was to provide energy planners and investors information to rank potential locations for future wind and photovoltaic (PV) installations based on quality of RE resources (specifically wind speed and solar irradiance for wind turbine and PV generation, respectively), relative capital costs by country, and proximity of potential sites to the transmission system. The method of evaluation was to integrate these factors into renewable energy supply curves for the South Asia region that could be used to characterize and compare potential sites on an equivalent cost basis. This work was also designed to aid planners in cost comparisons with other energy sources. RE costs are subject to added considerations relative to conventional fuels because the amount of generation will vary based on diurnal and seasonal characteristics and development at the highest quality resource sites may necessitate building access roads to bring in materials and a spur line to connect the site to the electrical grid. The supply curve analysis presented in this paper can be used to identify the most cost-effective locations for new RE development by comparing potential locations for RE deployment against one another to determine locations with the lowest site and transmission levelized cost of energy (LCOE) costs. The site LCOE (i.e., for each discrete location) is typically expressed as $\$ / \mathrm{MWh}$ and is the minimum price at which electricity must be sold for an energy project to break even, taking into consideration initial investment costs, operations and maintenance, fuel, and cost of capital $^{1}$. The supply curve aggregates discrete locations spatially to summarize available land area, capacity, net capacity factor, site LCOE and grid interconnection costs across the region of interest.

${ }^{1}$ https://www.nrel.gov/analysis/tech-lcoe-documentation.html 


\section{Methodology}

\section{Resource Data and Performance Modeling}

This effort leveraged existing wind and solar data sets for South Asia (including India, Nepal, Bhutan, Bangladesh, and Sri Lanka) to examine how the cost of wind and PV generation vary across the region. The characteristics of the resource data sets are described below.

Assessment of the potential wind and PV electricity generation requires accurate resource data with high spatial and temporal resolutions. The spatial variability of wind resource is typically higher than that of solar irradiance, due to the influence changes in terrain can have on wind speed. Therefore, the spatial resolution of wind resource is generally finer than that of solar resource for supply curve modeling. Both wind and solar resource present high variability across time, requiring high temporal resolution time series data (e.g., hourly time steps) to accurately simulate electricity generation. Wind resource estimates wind speed and direction, air temperature and atmospheric pressure at multiple heights above the ground surface for modeling different turbines (e.g., hub heights of 80,100 or $120 \mathrm{~m}$ ). Solar irradiance data typically capture direct normal irradiance (DNI), diffuse horizontal irradiance (DHI), air temperature, and wind speed at the surface. DNI is the incoming irradiance directly from the sun; DHI is scattered in the atmosphere or reflected by other surfaces. These variables are used for calculating power output for a specified (wind or PV) system at individual locations, across the time series. Whenever possible, modeling based on multiple years of resource data is recommended to capture interannual variability well enough to estimate long-term trends in regional resource quality.

\section{Solar resource data}

The solar data used in this work cover India, Nepal, Bhutan, Bangladesh, and Sri Lanka. These data were modeled through a collaboration between NREL, the State University of New York (SUNY)-Albany, and Solar Consulting Services. The data were modeled at a spatial resolution of 0.1 degrees in both latitude and longitude $(\sim 10 \mathrm{~km})$, and system performance was characterized using the full hourly data from 2000 to 2014.

\section{Wind resource data}

The wind resource data for this study cover most regions of India, Bangladesh, and Nepal, and all of Sri Lanka (Figure 1). NREL produced this data using the Weather Research and Forecasting (WRF) model (version 3.7) at a nominal spatial resolution of $3 \mathrm{~km}^{2}$ and a temporal resolution of 5-minutes. Due to limited funding, this data set was only produced for 2014 and includes 50, 80, 100 and $120 \mathrm{~m}$ heights above ground surface. 


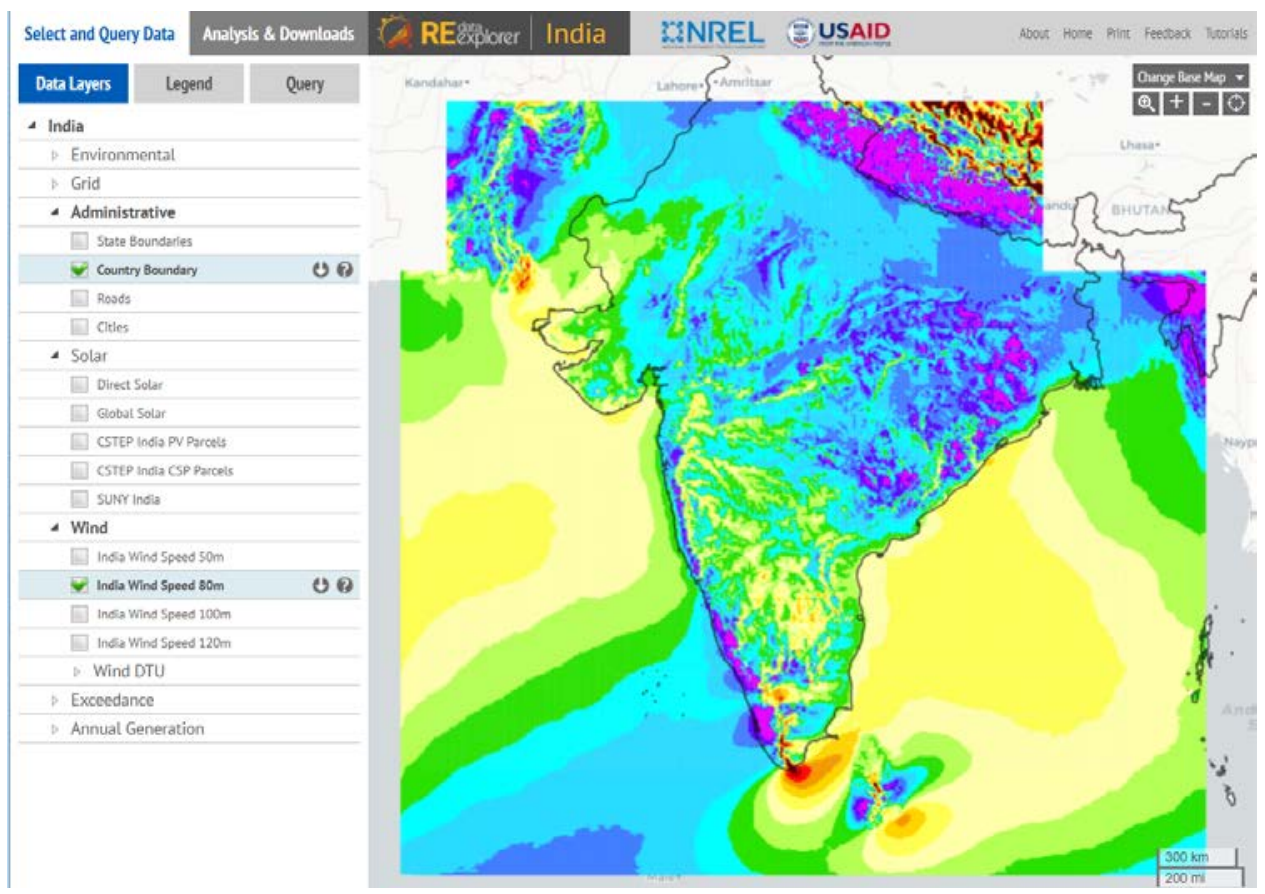

Figure 1. 2014 modeled wind resource extent used in this analysis (RED-E India, https://maps.nrel.gov/rede-india).

\section{Renewable Energy Potential (reV) model}

This analysis used NREL's renewable energy potential (reV) modeling framework to calculate generation potential, excluding potentially undevelopable lands, and calculating grid connection costs and supply curves. The reV model utilizes the System Advisor Model (SAM) for calculating system performance. Inputs into SAM include time series resource data, system configurations, and financial parameters to estimate electricity generation and site LCOE. SAM calculates performance and cost for discrete locations, but by using the reV model, multiple locations can be run in parallel. In all, 750,000 wind resource points and 100,000 solar resource points were analyzed using the reV model.

Once the performance and cost data were generated for each resource point, areas of land that were either restricted or undesirable for development were removed from consideration. The remaining areas of land were then aggregated by resource quality into sections of land roughly $5.7 \mathrm{~km}^{2}$ in area to create a consistent grid layout of potential sites for wind and PV. Spur lines were drawn as a simplified representation of new transmission features that would need to be installed to connect these potential sites to the electrical grid. The grid interconnection cost for each potential site was calculated along the spur line as a function of Euclidean distance to the closest electricity grid feature (e.g., existing transmission lines or substations).

External to the reV framework, the cost of building roads to the resource site was similarly calculated using Euclidean distance to the nearest road feature. The grid connection and road building cost are incorporated into the estimate of total cost to develop a resource site. 


\section{Solar: Utility-Scale PV}

Generation was simulated for a fixed open rack PV system with the tilt set to a site's latitude (see Appendix A for system configuration). Using the solar resource data described above, the multiyear generation (from 2000 through 2014) was calculated to determine net capacity factors at each location. The net capacity factor describes the percent output of the system's design rating (i.e., the nameplate rating) that can be expected in a single year, and includes system losses (panel soiling, shading, electrical components and degradation).

The power density for the PV system was assumed to be $32 \mathrm{MW} / \mathrm{km}^{2}$, which is used as a guideline to define the maximum capacity installable in a square kilometer for a system of this type. This power density value was based on research on the area required for PV systems at various scales (Ong et al, 2013). Undesirable or restricted areas were identified as protected areas, areas with slope $>5 \%$, urban areas, water bodies and wetland/flooded areas for this technology (Brown et al, 2016).

\section{Utility-Scale Wind (Land-Based)}

The turbine characteristics used in this study were based on generic components that would likely be installed at the time of writing. The power curve of a given turbine specifies the power output as a function of wind speed (See Appendix A). Three turbine classes, following the IEC conventions, were modeled to account for variability in wind speed across the countries of interest utilizing the wind resource data at $80 \mathrm{~m}$ above ground surface. A single turbine is not appropriate for all locations; areas with lower average wind speed call for a larger rotor diameter (i.e., longer blades) and a power curve that generates more electricity at lower wind speeds. On the contrary, higher wind speed locations require a smaller rotor diameter and a power curve designed for higher sustained wind speeds. Turbine class configurations are detailed in Appendix A.

The power density assumed for these turbines was $3 \mathrm{MW} / \mathrm{km}^{2}$ (Ong et al, 2013; Denholm et al, 2009). Undesirable or restricted areas were identified as protected areas, areas with slope $>20 \%$, urban areas, water bodies and wetland/flooded areas for this technology (Brown et al, 2016). Given that the wind resource data set was not available for the entire study area and was only run for one year, the wind analysis presented here should be considered preliminary.

\section{Cost Assumptions}

The economic assumptions developed by Deshmukh, Wu, and Phadke (2017, Tables 2.4 and 2.5) for India were considered the most rigorous and up-to-date available. Similar financial modeling has not been conducted for other countries in this study, therefore these assumptions were applied to all countries (Table 1). 
Table 1. Cost Assumptions

\begin{tabular}{|c|c|c|}
\hline Variable & Utility-Scale PV & Utility-Scale Wind \\
\hline Overnight Capital cost (\$/MW) & 810,000 & 950,000 \\
\hline Fixed O\&M cost (\$/MW) & 10,455 & 16,788 \\
\hline Fixed-charge rate (FCR) & 0.0545 & 0.0545 \\
\hline Lifetime & 25 years & 25 years \\
\hline Variable & Transmission & Roads \\
\hline Capital cost & $\begin{array}{c}450 \\
\$ / \mathrm{MW} / \mathrm{km}\end{array}$ & $407,000 \$ / \mathrm{km}$ \\
\hline Fixed O\&M cost (\$/MW) & 0 & 0 \\
\hline Substation cost (\$/substation) & 17,500 & - \\
\hline
\end{tabular}

The analysis calculated the site LCOE for generation (LCOEgen) and the total LCOE (LCOEtot), including the site LCOE, the cost to build a road to the site from the nearest existing road and the grid interconnection cost.

$$
\begin{aligned}
& \text { LCOEgen }=(\text { FCR * Capital Cost }+ \text { Fixed O\&M }) /(8760 * \text { Net Capacity Factor }) \\
& \text { LCOEroad }=((\text { Road Distance }[\mathrm{km}] * \text { FCR * Capital Cost })+\text { Fixed O\&M }) /(8760 * \text { Net } \\
& \text { Capacity Factor * Site Capacity }[\mathrm{MW}]) \\
& \text { LCOEtrans }=(((\text { Transmission Distance }[\mathrm{km}] * \text { FCR * Capital Cost })+\text { Fixed O\&M })+ \\
& (\text { Substation Cost } * 2)) /(8760 * \text { Net Capacity Factor }) \\
& \text { LCOEtot }=\text { LCOEgen }+ \text { LCOEroad + LCOEtrans }
\end{aligned}
$$

The resource data were discretized into individual sites with an associated area and capacity factor. The amount of capacity associated with each site will vary depending on the technical exclusions. Figures 1 and 2 show the distribution of the LCOEgen and LCOEtot over the region for utility-scale PV, and Figures 3 and 4 show the distribution for utility-scale wind. Note that sites that have low amounts of capacity will have significantly higher road costs when levelized. 

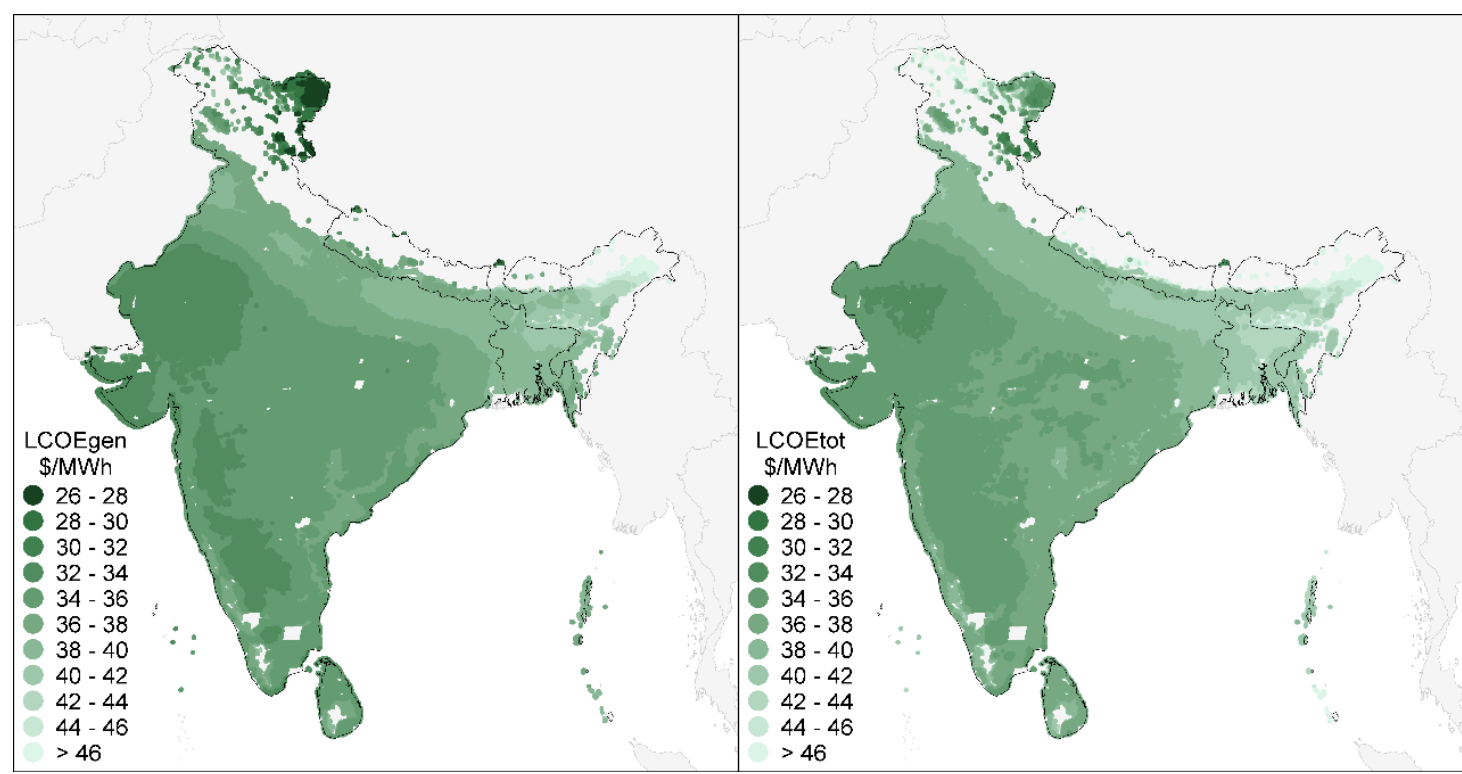

Figure 2. Levelized generation cost (LCOEgen) and total cost (LCOEtot; generation + road + transmission) for utility-scale PV

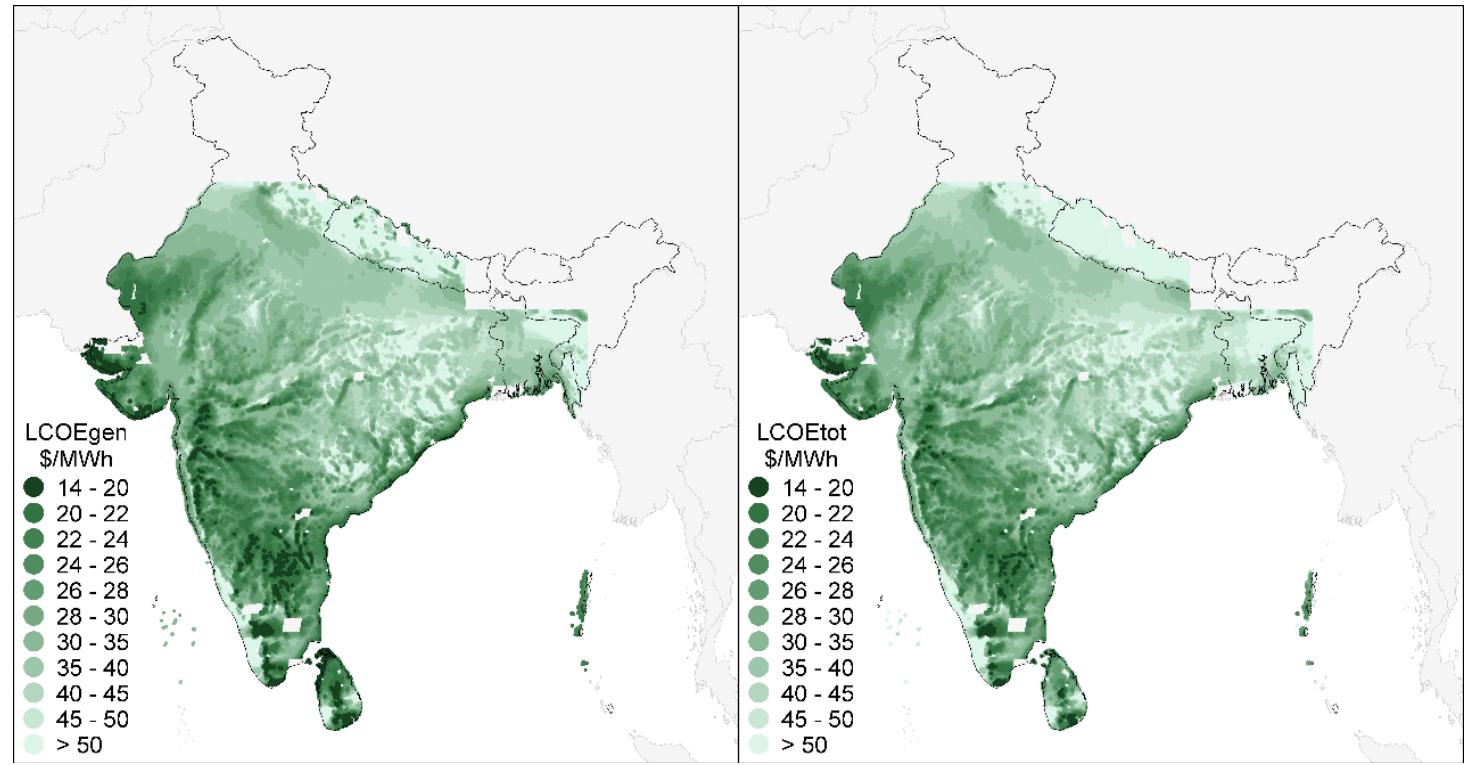

Figure 3. Levelized generation cost (LCOEgen) and total cost (LCOEtot; generation + road + transmission) for utility-scale wind 


\section{Analysis Results}

The results of the cost analysis can be integrated into a series of supply curves for a given area, allowing for comparison of the potential supply of a renewable resource at specific price points of interest. These could include the cost of energy from other fuel sources, the impact of incentives, and comparison to utility purchase price proposals. Figures 5 and 6 show the lowest cost $10 \mathrm{GW}$ of potential using total LCOE by country for utility-scale PV and wind. The full supply curves, and a separate set of supply curves for the generation LCOE alone, are provided in Appendix B.

It should be noted that by including roads in the LCOE, the total LCOE results are biased toward sites with the greatest area because the fixed road cost is levelized over more potential generation. The range of LCOE values for generation and total cost for wind also tend to be much higher than for utility-scale PV in this analysis because the range of net capacity factors for utility-scale PV sites in the analysis is $11 \%-24 \%$, while most capacity factors for wind fall between $20-30 \%$. Partly, this reflects the relative resource quality and performance characteristics of the technologies, but it is also due the fact that wind is being represented by only one year of modeled data. The high and low values may not represent the long-term mean that could be expected at that site. LCOEtot is also influenced by the higher installation density of utility-scale solar, which reduces the LCOEroad component of the total LCOE as compared to wind.

While these results have been summarized by country, the resource sites can be indexed and summarized to any desired geographical entity (so long as the entity is larger than the site aggregation of roughly $5.7 \mathrm{~km}^{2}$ ). The results can also be explored visually through a map interface using the Renewable Energy Data Explorer (RED-E) ${ }^{2}$ platform, and they can be filtered based on cost or other parameters in the database.

\footnotetext{
${ }^{2}$ https://www.re-explorer.org/
} 


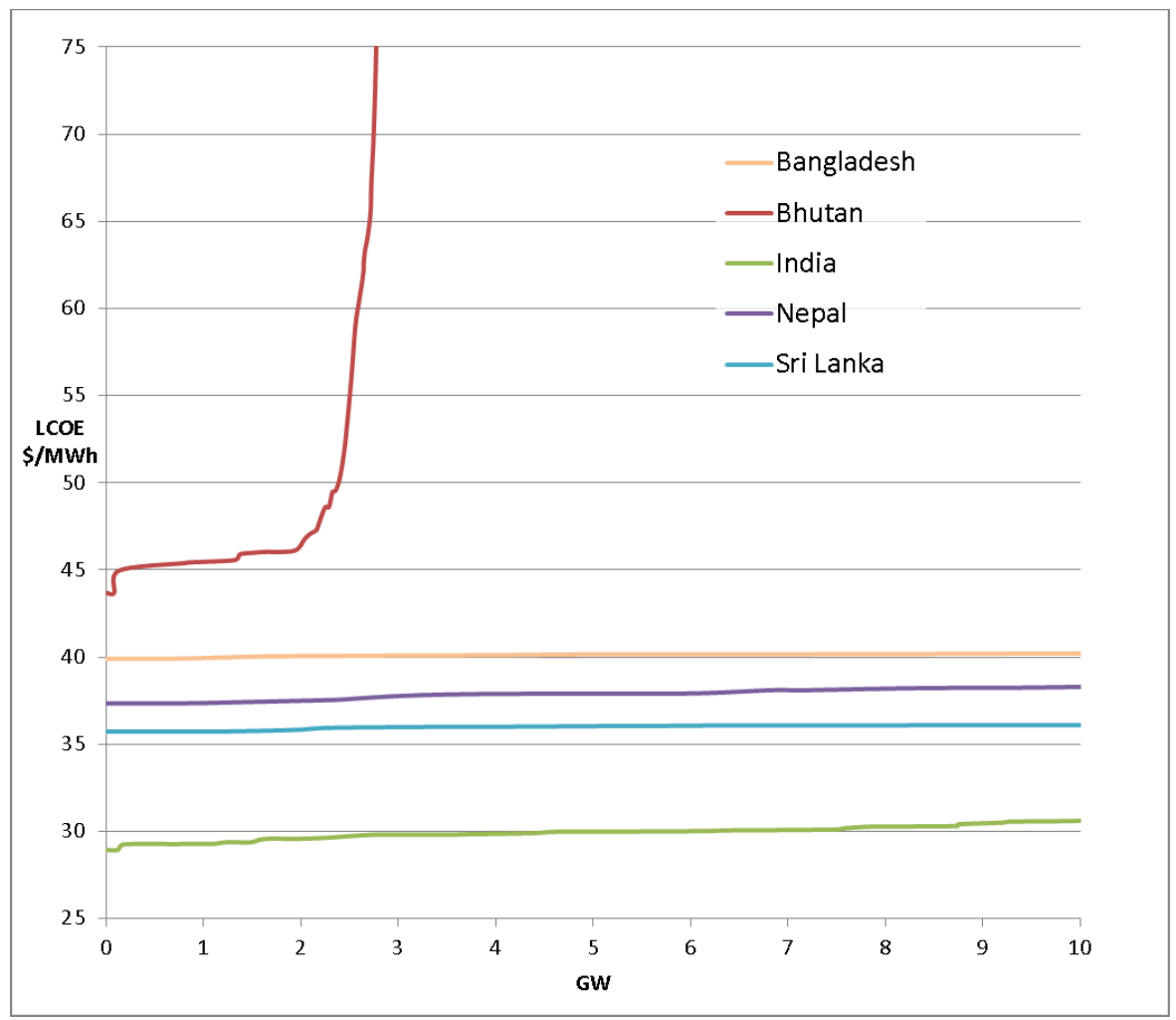

Figure 4. Lowest-cost $10 \mathrm{GW}$, LCOEtot supply curve for utility-scale PV, by country

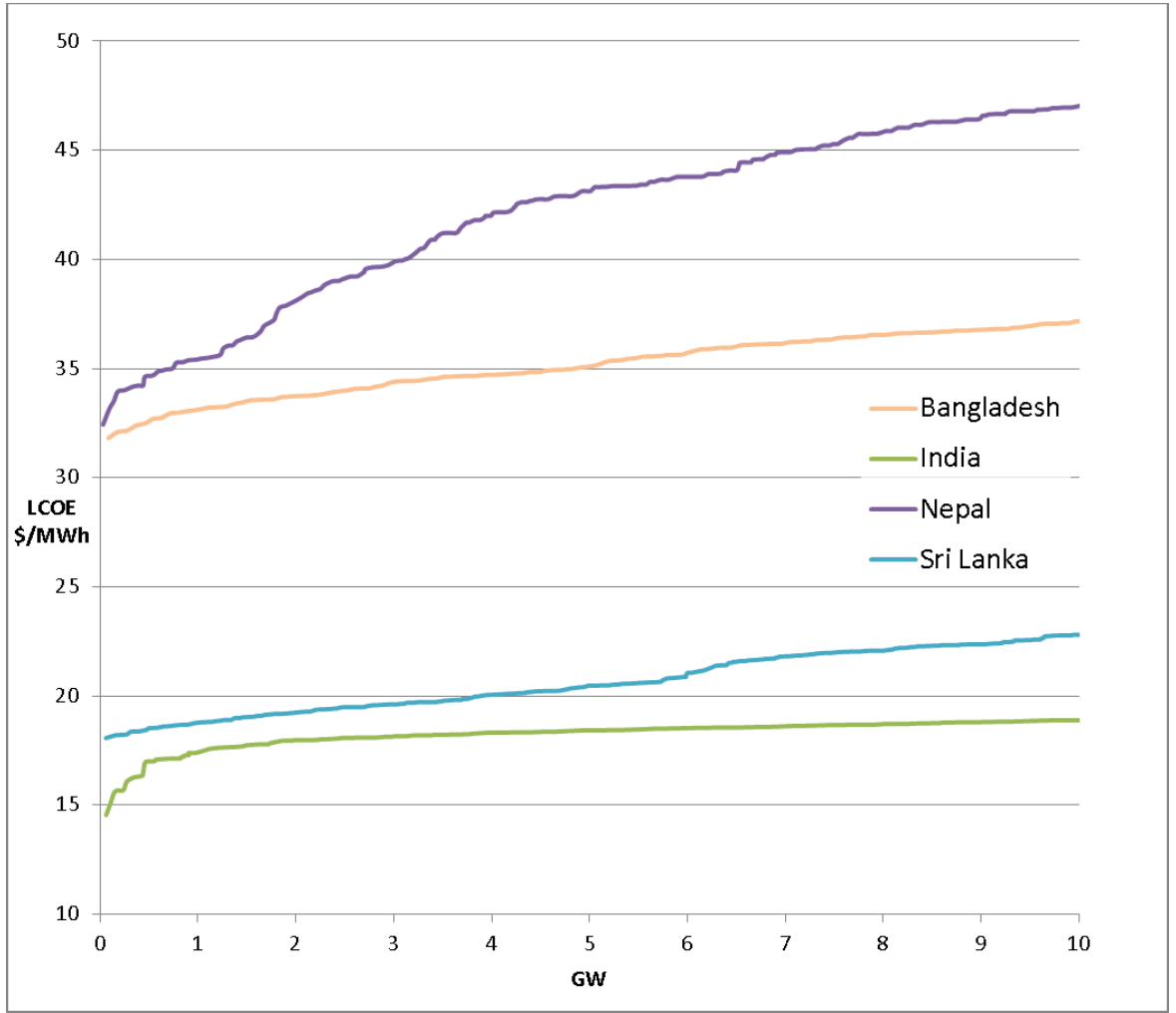

Figure 5. Lowest-cost $10 \mathrm{GW}$, LCOEtot supply curve for wind, by country 


\section{Conclusions}

The countries included in this analysis (India, Nepal, Bhutan, Bangladesh, and Sri Lanka) have significant utility-scale wind and solar PV potential, with the potential for competitive pricing in many high-quality resource areas. Tables 2 and 3 summarize the total technical potential and the estimated LCOE ranges determined for each country. This type of analysis is useful in (1) assessing the magnitude of the resource potential and (2) identifying areas - through high-level cost analysis - that have good potential for more detailed project evaluation. The summary tables include LCOE thresholds for the lowest-cost of 1 and $10 \mathrm{GW}$ potential capacity; in most cases, moving from 1 to $10 \mathrm{GW}$ of potential adds only a few \$/MWh to the LCOE. The high-cost tails of the computed LCOE ranges are heavily influenced by low capacity factors in poor quality resource areas for LCOEgen, and by small capacity sites in LCOEtot that result in the road cost being levelized over a very small amount of potential generation.

This methodology and initial results are available through an economic potential tool that NREL developed for India (https://maps.nrel.gov/gst-india). The economic potential tool uses as defaults the cost parameters and technical potential framework presented within this paper. However, within that tool, an analysis can be customized by changing some of those default values to simulate reductions in system costs and maintenance, capital recovery timeframes, and changes to the other cost components considered (road and transmission costs).

Table 2. Utility-Scale PV: Resource and Cost Summary

\begin{tabular}{|c|c|c|c|c|c|c|c|}
\hline Country & $\begin{array}{l}\text { Technical } \\
\text { Potential } \\
\text { (GW) }\end{array}$ & $\begin{array}{l}\text { LCOEgen } \\
\text { Range } \\
\text { (\$/MWh) }\end{array}$ & $\begin{array}{l}\text { LCOEtot } \\
\text { Range } \\
\text { (\$/MWh) }\end{array}$ & $\begin{array}{l}1 \mathrm{GW} \\
\text { Potential, } \\
\text { LCOEgen }\end{array}$ & $\begin{array}{l}1 \text { GW } \\
\text { Potential, } \\
\text { LCOEtot }\end{array}$ & $\begin{array}{l}10 \mathrm{GW}^{\mathrm{a}} \\
\text { Potential, } \\
\text { LCOEgen }\end{array}$ & $\begin{array}{l}10 \mathrm{GW}^{\mathrm{a}} \\
\text { Potential, } \\
\text { LCOEtot }\end{array}$ \\
\hline Bangladesh & 2,838 & $37-43$ & $40-3,133$ & 37.3 & 40.0 & 37.5 & 40.2 \\
\hline Bhutan & 3 & $36-47$ & $44-647$ & 43.6 & 45.6 & 46.7 & 647.1 \\
\hline India & 61,028 & $26-56$ & $29-3,210$ & 26.2 & 29.3 & 26.4 & 30.6 \\
\hline Nepal & 381 & $30-44$ & $37-2,761$ & 35.3 & 37.4 & 35.9 & 38.3 \\
\hline Sri Lanka & 736 & $34-40$ & $36-2,720$ & 33.8 & 35.7 & 34.3 & 36.1 \\
\hline
\end{tabular}

a Value reflects Bhutan's maximum LCOE, as total technical potential is less than $10 \mathrm{GW}$ of capacity.

Table 3. Utility-Scale Wind: Resource and Cost Summary

\begin{tabular}{|c|c|c|c|c|c|c|c|}
\hline Country & $\begin{array}{l}\text { Technical } \\
\text { Potential } \\
\text { (GW) }\end{array}$ & $\begin{array}{l}\text { LCOEgen } \\
\text { Range } \\
\text { (\$/MWh) }\end{array}$ & $\begin{array}{l}\text { LCOEtot } \\
\text { Range } \\
\text { (\$/MWh) }\end{array}$ & $\begin{array}{l}1 \text { GW } \\
\text { Potential, } \\
\text { LCOEgen }\end{array}$ & $\begin{array}{l}1 \mathrm{GW} \\
\text { Potential, } \\
\text { LCOEtot }\end{array}$ & $\begin{array}{l}10 \mathrm{GW} \\
\text { Potential, } \\
\text { LCOEgen }\end{array}$ & $\begin{array}{l}10 \mathrm{GW} \\
\text { Potential, } \\
\text { LCOEtot }\end{array}$ \\
\hline Bangladesh & 349 & $25-328$ & $32-37,491$ & 26.4 & 33.1 & 29.5 & 37.2 \\
\hline India & 7,862 & $14-1,052$ & $15-92,004$ & 16.6 & 17.4 & 18.1 & 18.9 \\
\hline Nepal & 83 & $21-1,093$ & $32-492,064$ & 31.5 & 35.4 & 40.9 & 47.1 \\
\hline Sri Lanka & 99 & $16-126$ & $18-16,890$ & 17.5 & 18.8 & 19.0 & 22.8 \\
\hline
\end{tabular}




\section{References}

Brown, A., Beiter, P., Heimiller, D., Davidson, C., Denholm, P., Melius, J., Lopez, A., Hettinger, D., Mulcahy, D., Porro, G. (2016). Estimating Renewable Energy Economic Potential in the United States: Methodology and Initial Results. National Renewable Energy Laboratory, Golden, CO: NREL/TP-6A20-64503, 154 pp.

Denholm, P., Hand, M., Jackson, M., \& Ong, S. (2009). Land use requirements of modern wind power plants in the United States (No. NREL/TP-6A2-45834). National Renewable Energy Laboratory, Golden, CO: NREL/TP-6A2-45834, 46pp.

Deshmukh, R., Wu, G., Phadke, A. (2017). Renewable Energy Zones for Balancing Siting Trade-offs in India: Multicriteria Analysis for Planning Renewable Energy (MapRE). Lawrence Berkeley National Laboratory, Berkeley, CA: LBNL-1007272. https:/eta.lbl.gov/sites/all/files/publications/india_renewable_energy_zones.pdf.

Ong, S.; Campbell, C.; Denholm, P.; Margolis, R.; Heath, G. (2013). Land-Use Requirements for Solar Power Plants in the United States. Golden, CO: NREL/TP-6A20-56290, 47pp. 


\section{Appendix A: PV and wind system configurations}

PV generation is based on the following system configuration:

- Azimuth: 180 degrees

- Ground Cover Ratio (GCR): 0.4

- Losses: $14 \%$

- Array Type: Fixed

- Tilt: Equal to Latitude

- Module Type: Standard

- Inverter Efficiency: 96\%

- DC/AC Ratio: 1.1

- System Capacity $\left(1,100 \mathrm{~kW}_{\mathrm{dc}}, 1,000 \mathrm{~kW}_{\mathrm{ac}}\right)$

Three wind turbines were modeled across the countries of interest. Mean annual wind speed was used to assign the appropriate turbine to each location:

- Class 1: wind speed $>9 \mathrm{~m} / \mathrm{s}$

- Class 2: $8 \mathrm{~m} / \mathrm{s}<$ wind speed $<=9 \mathrm{~m} / \mathrm{s}$

- Class 3: wind speed $<=8 \mathrm{~m} / \mathrm{s}$

The configurations for all three turbines include:

- Hub height: 80 meters from the surface

- Shear coefficient: 0.14

- Turbulence Coefficient: 0.1

- Rate output: 2,000 kW

- Energy losses: $15 \%$

The rotor diameter was set individually for each turbine:

Class 1:77m

Class 2: $82.5 \mathrm{~m}$

Class 3: $100 \mathrm{~m}$ 
Below are the three power curves:
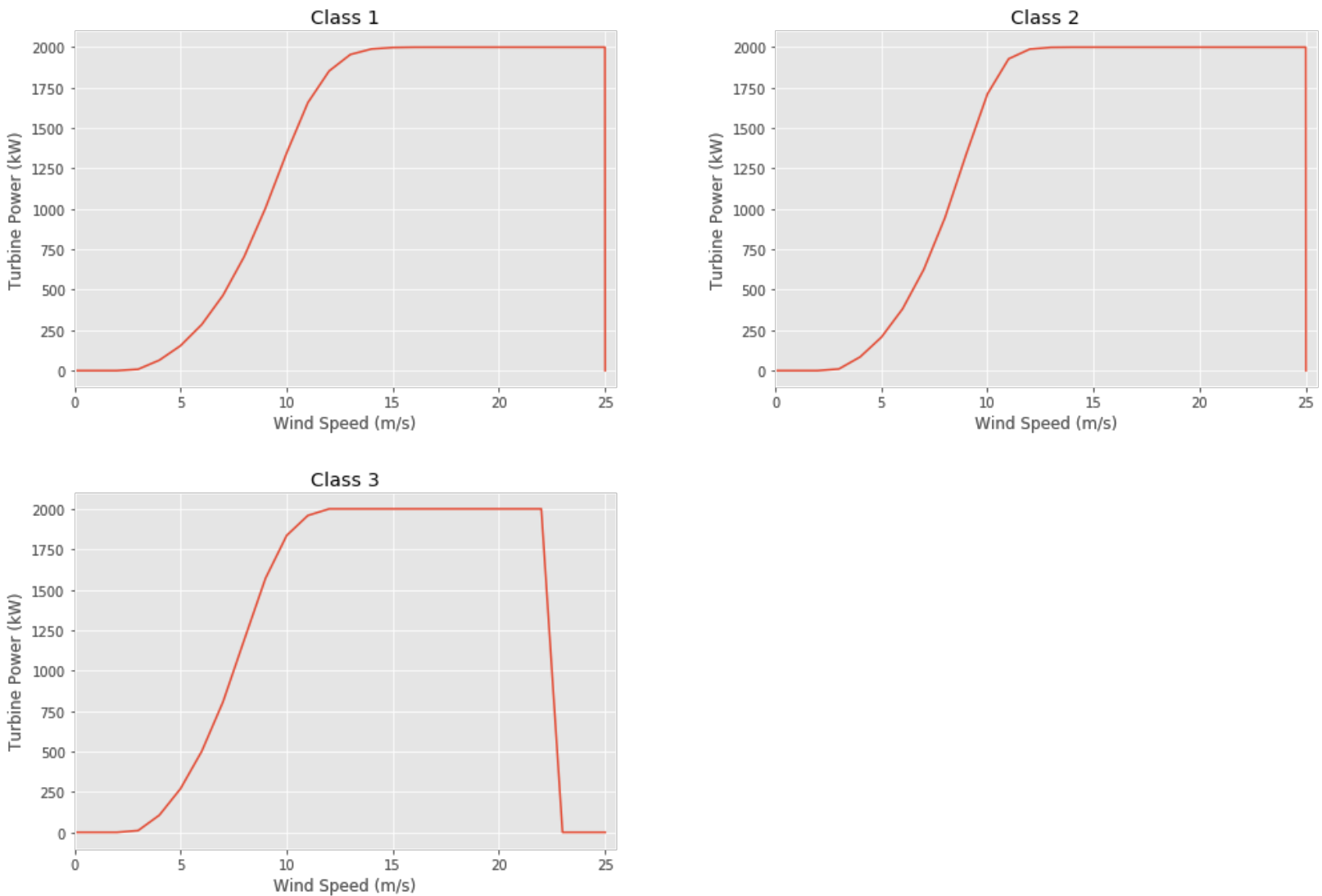

This report is available at no cost from the National Renewable Energy Laboratory (NREL) at www.nrel.gov/publications. 


\section{Appendix B: Full utility-scale PV and wind supply curves}

Supply curves are provided for utility-scale PV and wind. The supply curves show results for LCOEgen as well as LCOEtot and include the full supply curve as well as a more detailed look at the lowest cost $10 \mathrm{GW}$.

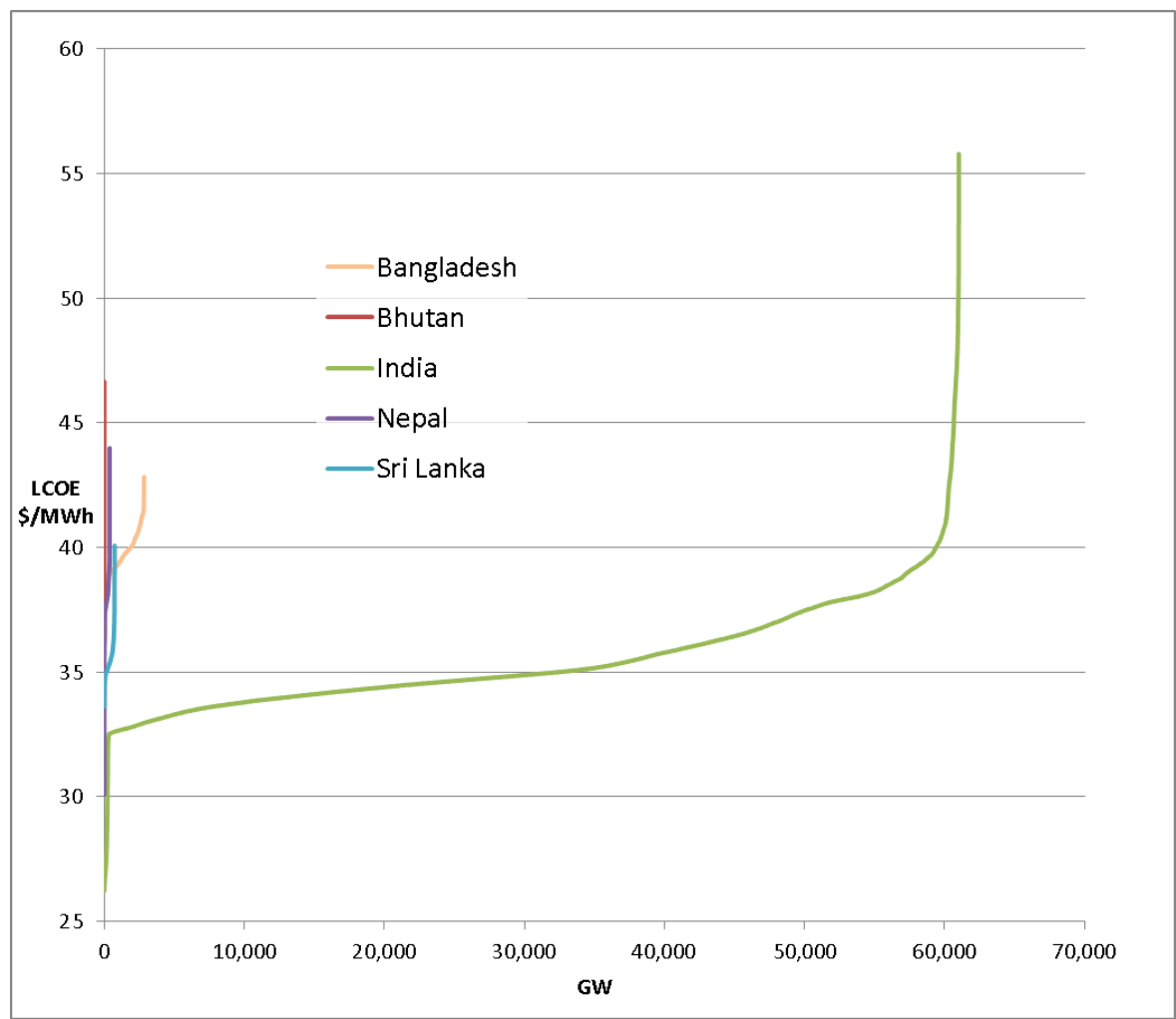

Figure B-1. LCOEgen supply curve for utility-scale PV, by country 


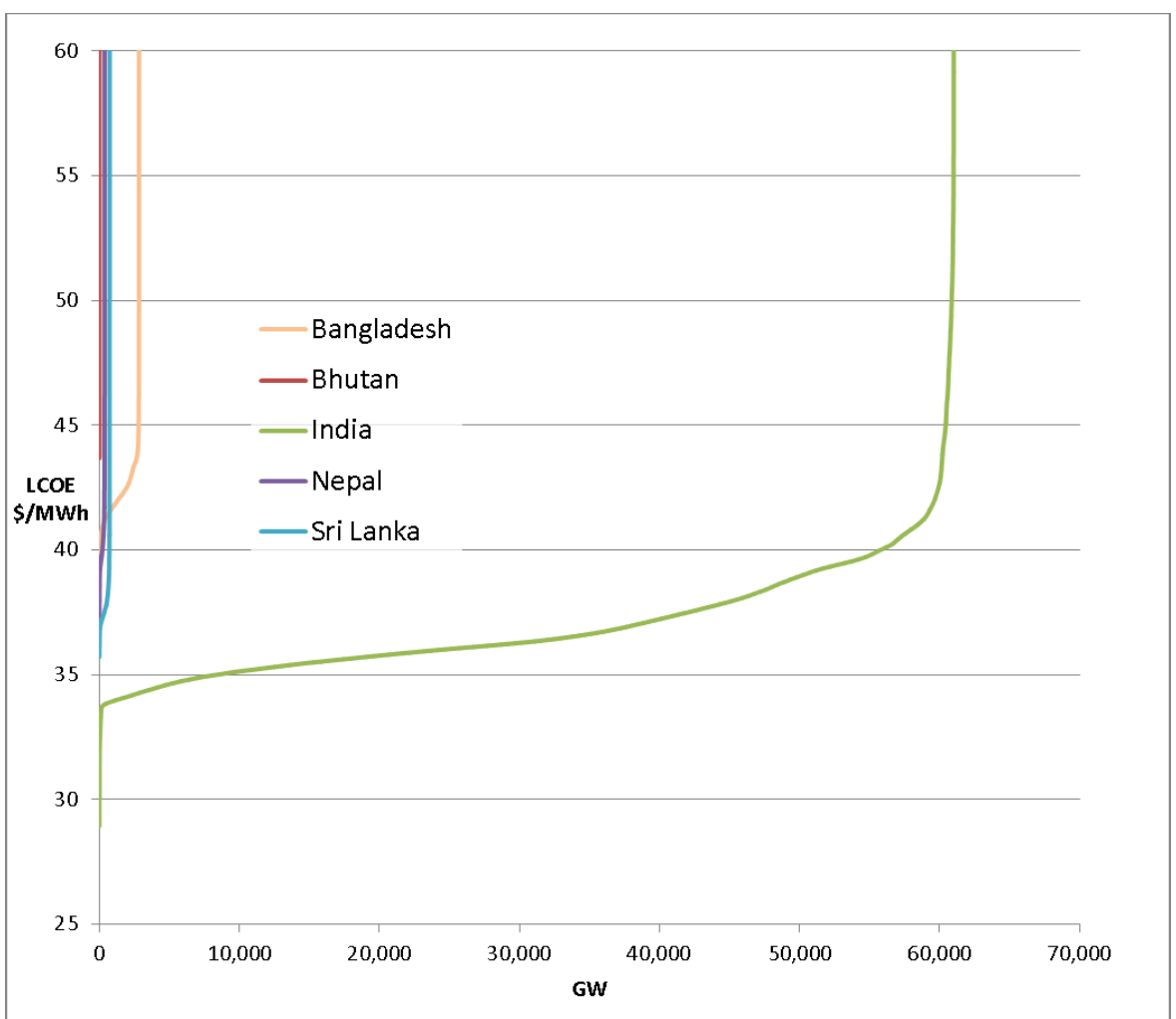

Figure B-2. LCOEtot supply curve for utility-scale PV, by country

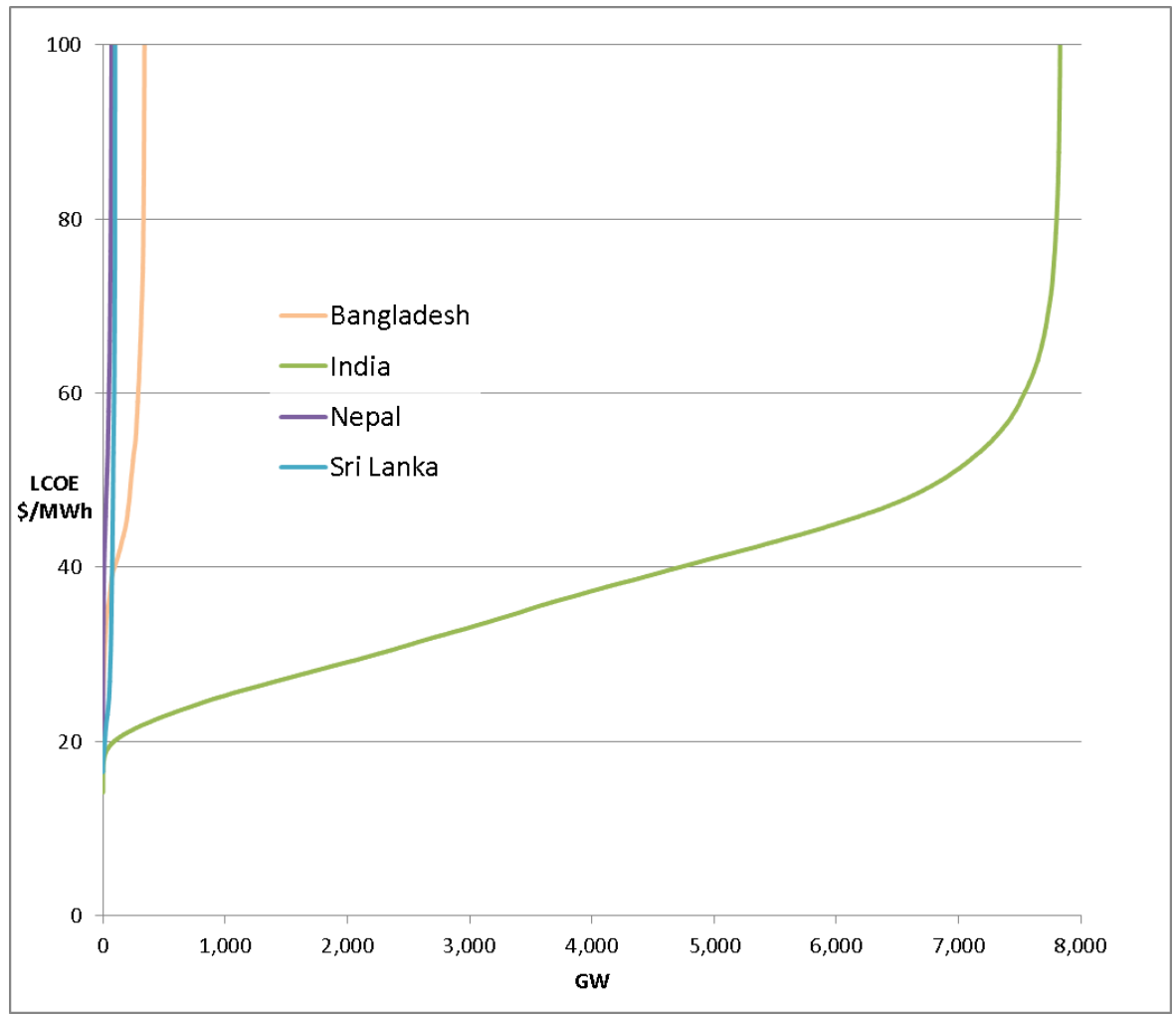

Figure B-3. LCOEgen supply curve for wind, by country 


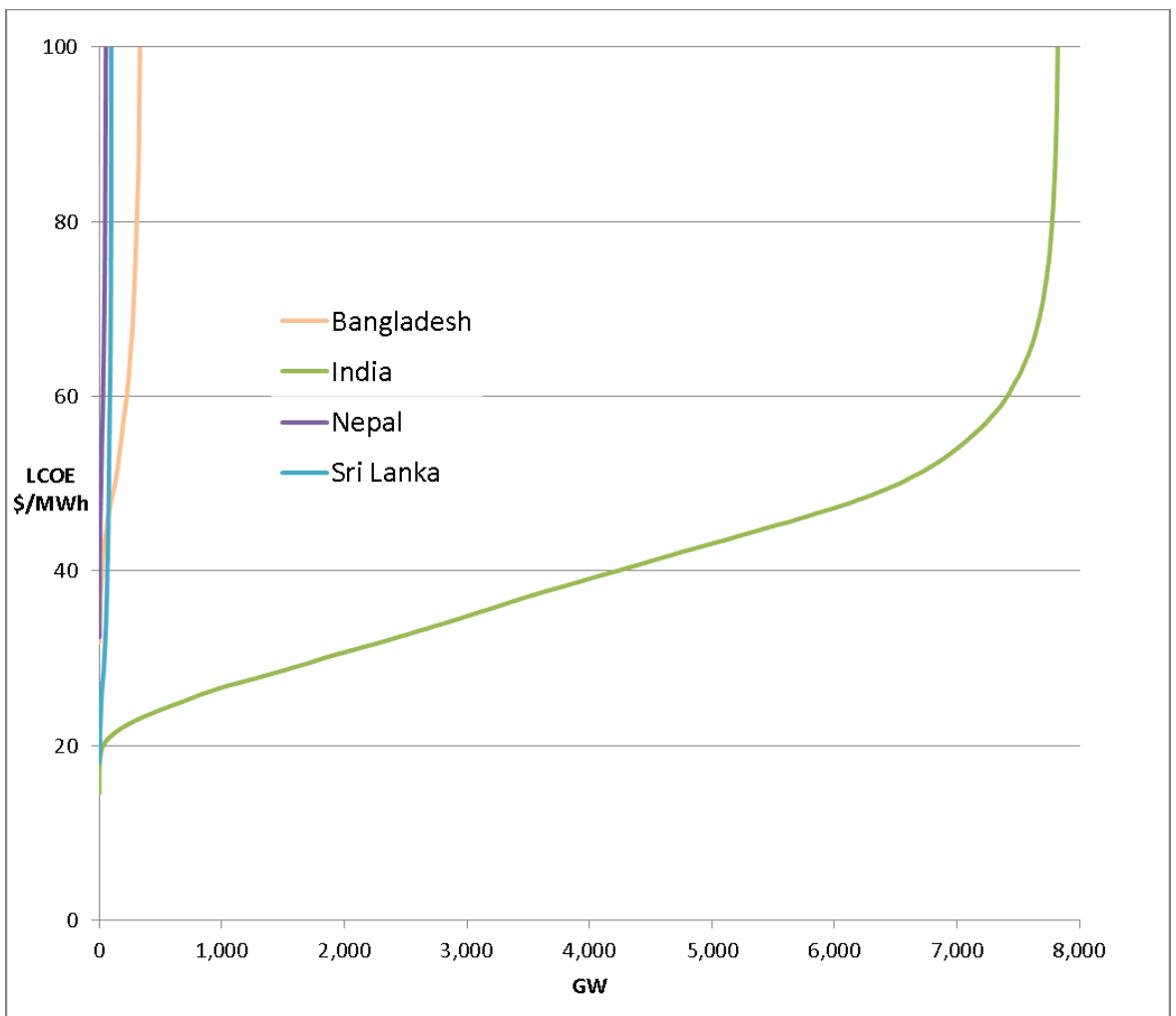

Figure B-4. LCOEtot supply curve for wind, by country

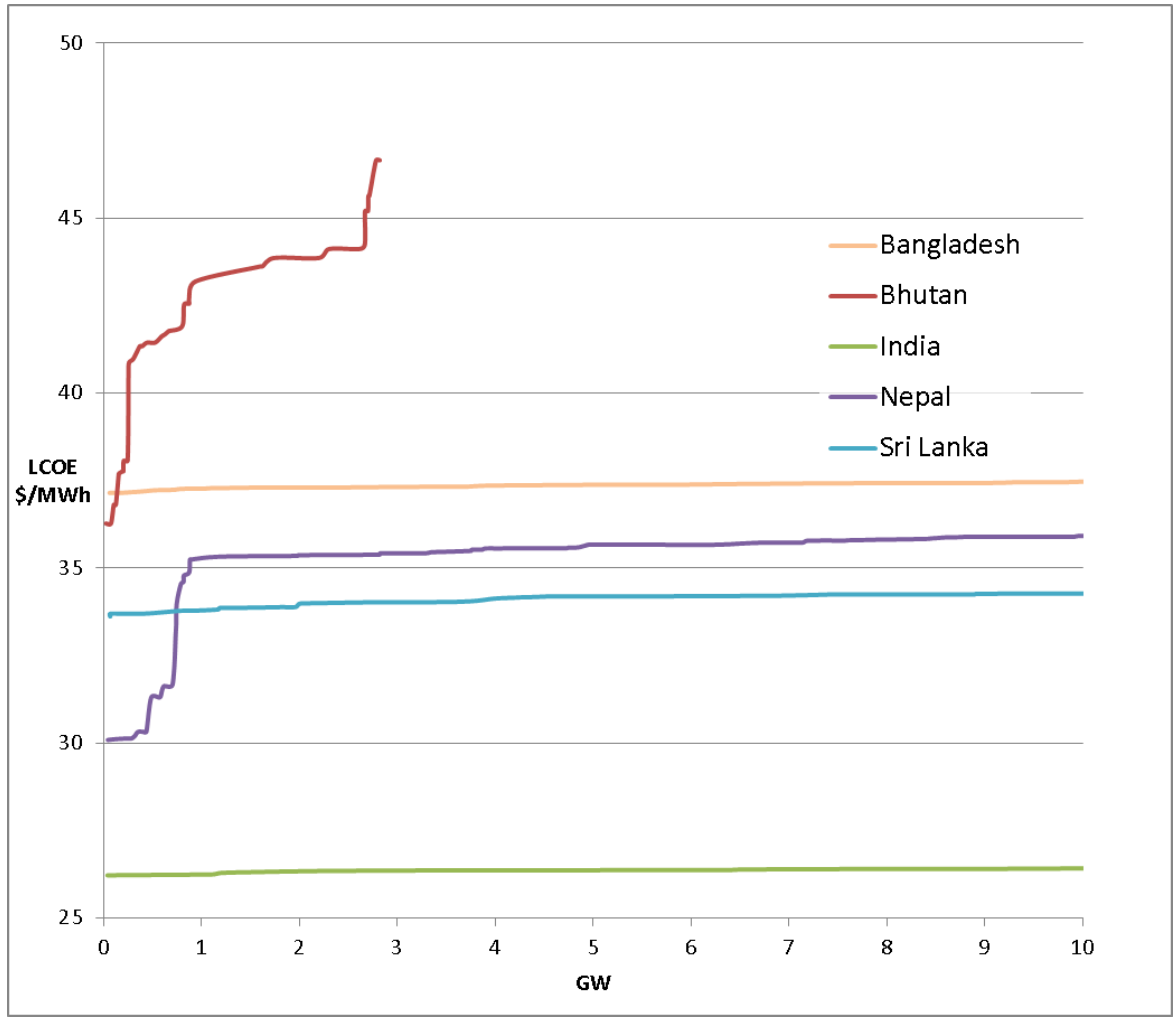

Figure B-5. Lowest-cost 10 GW, LCOEgen supply curve for utility-scale PV, by country 


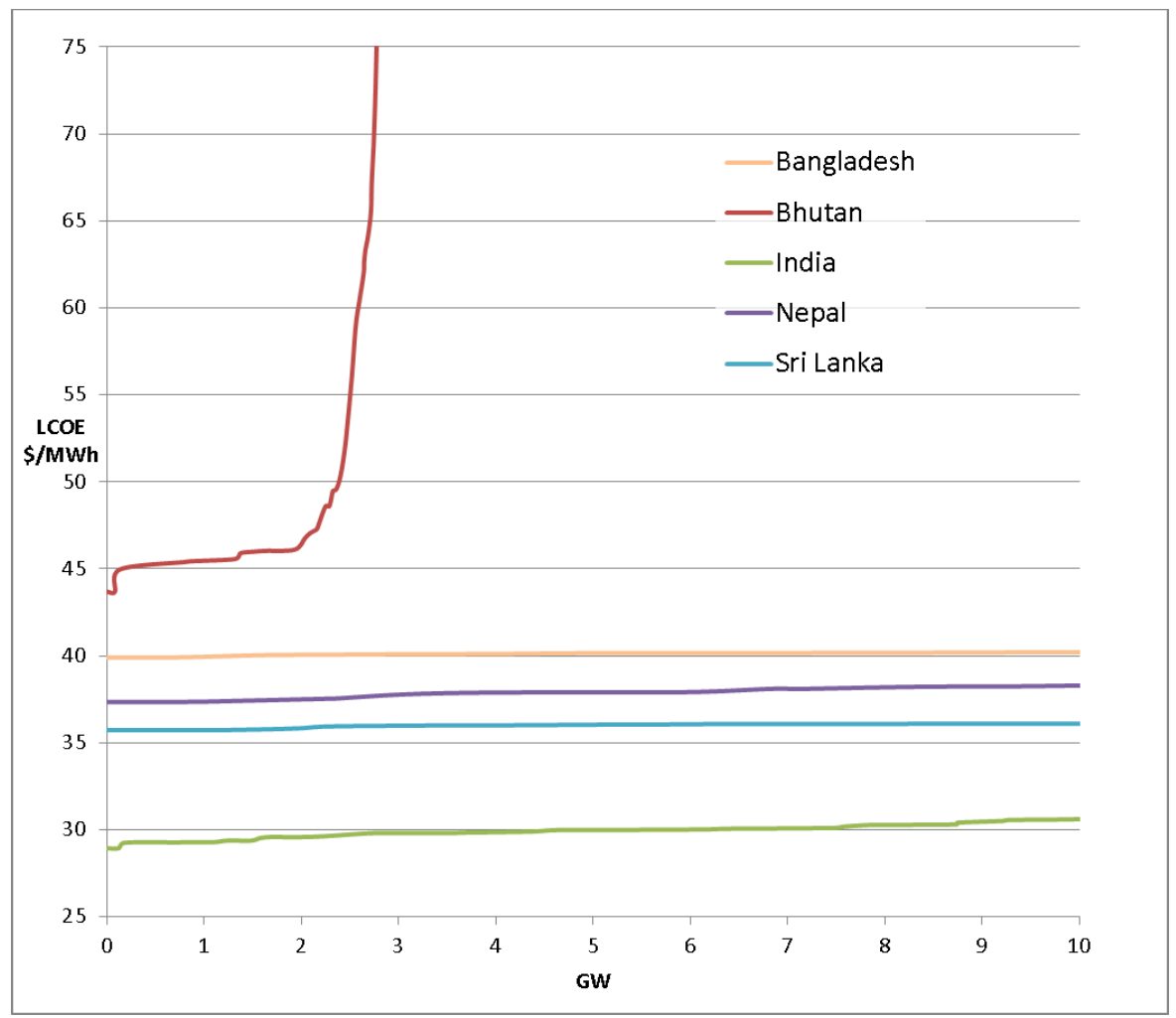

Figure B-6. Lowest-cost 10 GW, LCOEtot supply curve for utility-scale PV, by country

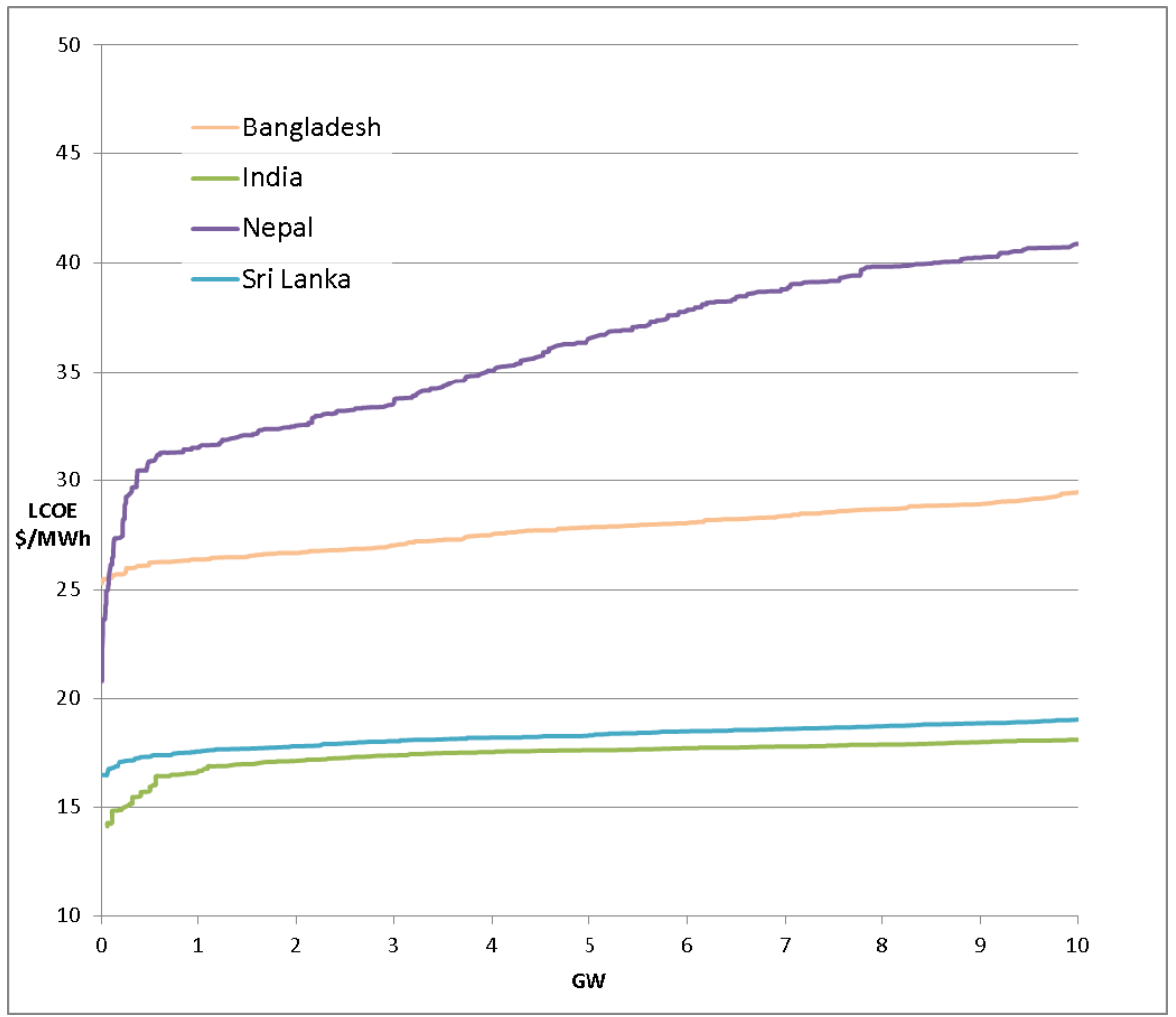

Figure B-7. Lowest-cost 10 GW, LCOEgen supply curve for wind, by country 


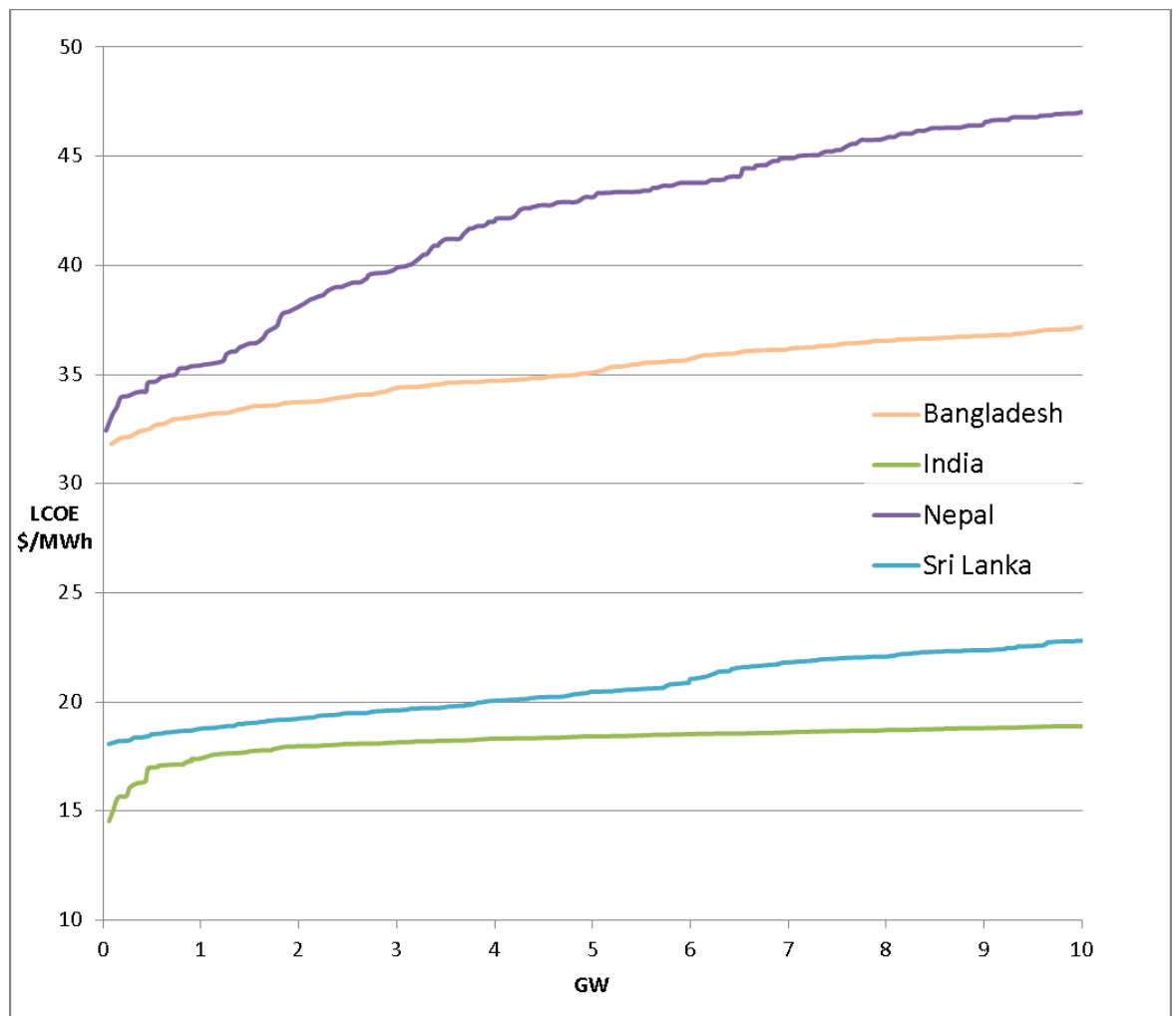

Figure B-8. Lowest-cost $10 \mathrm{GW}$, LCOEtot supply curve for wind, by country 